\title{
Urinary zinc stable isotope signature as indicator for cancer types with disrupted zinc metabolism
}

\author{
KATHRIN SCHILLING ${ }^{1}$ ALEX N. HALLIDAY ${ }^{2}$ AlastaIR \\ LAMB $^{3}$ TATJANA CRNOGORAC-JURCEVIC ${ }^{4}$ FIONA \\ LARNER $^{5}$ \\ ${ }^{1}$ Lamont-Doherty Earth Observatory, Palisades, NY, USA \\ (kathrins@1deo.columbia.edu) \\ ${ }^{2}$ Earth Institute, Columbia University, New York, NY, USA \\ ${ }^{3}$ Dept. Surgical Sciences, University of Oxford, Oxford, UK \\ ${ }^{4}$ Barts Cancer Institute, Queen Mary University London, \\ London, UK \\ ${ }^{5}$ Dept. Earth Sciences, University of Oxford, Oxford, UK
}

Zinc $(\mathrm{Zn})$ is an essential biometal which determines the catalytic and structural role of proteins. Its abundance is generally tightly regulated in the human body. Cancer development and progression dysregulates the $\mathrm{Zn}$ abundance in the body. Pancreatic, breast and prostate cancers are all known to alter the $\mathrm{Zn}$ metabolism. Diagnostic and prognostic tools for early detection of pancreatic cancer and more reliable diagnosis of prostate cancer are urgently needed. Urinary $\mathrm{Zn}$ concentrations and $\mathrm{Zn}$ stable isotope signature $\left(\delta^{66 / 64} \mathrm{Zn}\right)$ may be a non-invasive approach in tracing malignancy-induced changes in $\mathrm{Zn}$ metabolism.

Our results show that statistically significant $\mathrm{Zn}$ concentration and isotopic changes $(p=0.002)$ are present in the urine of pancreatic cancer patients $(n=17)$ that are not seen in healthy controls $(n=33)$. The preferential excretion of isotopically light $\mathrm{Zn}$ in pancreatic cancer likely reflects the dysregulation of metalloproteins. Urine samples from prostate cancer patients $(n=21)$ have been assessed to see if a disease related $\mathrm{Zn}$ isotopic shift in urine occurs, and if so, whether the $\mathrm{Zn}$ isotopic signature differs from that exhibited in pancreatic cancer patients. The analysis showed that the isotopic shift in $\mathrm{Zn}$ metabolism is not reflected in the urine as there is no systematic difference between the prostate cancer group and the male healthy controls $(\mathrm{n}=8 ; p=0.11)$. This can be explained by the vastly segregated prostate $\mathrm{Zn}$ cycle from other body fluids such as urine.

Thus, urinary $\mathrm{Zn}$ isotopes show promise as a novel, noninvasive approach for pancreatic cancer detection that can also help potentially detect $\mathrm{Zn}$ dysregulation compared to a healthy population and other types of cancer with an altered $\mathrm{Zn}$ metabolism (e.g., prostate cancer). 